\title{
Association Between Smoking, Acetaldehyde Dehydrogenase-2 1-1 Status, and Alcohol Drinking Among Taiwanese Polyvinyl Chloride Workers
}

\author{
Yi-Ping Lin, MS \\ Hui-I Hsieh, MD, MS \\ Yen-Cheng Chen, MS \\ Tsun-Jen Cheng, MD, ScD
}

To study the factors affecting alcohol consumption among Taiwanese workers, we conducted an investigation of the association between alcohol drinking and smoking, aldehyde dehydrogenase-2 (ALDH2) status, alcohol dehydrogenase-2 (ADH2) status, any history of abnormal liver function, and hepatitis $B$ and $C$ viral infection. The subjects included 207 male workers who had been followed-up with respect to liver function periodically since 1992. Information relating to current alcohol consumption and smoking habits was obtained by an interviewer-administered questionnaire in 1996, and any history of liver function and hepatitis B and $C$ virus infection was obtained from previous medical surveillance. Genotypes of ALDH2 and ADH2 were determined by polymerase chain reaction/restriction fragment polymorphism assay. Results have revealed that smoking and ALDH2 1-1 status were associated with current alcohol consumption (respectively: odds ratio, 23.3; $\mathrm{P}<0.01$ and odds ratio, 14.5; $\mathrm{P}<0.05)$. Neither a history of abnormal liver function nor a history of hepatitis $B$ and/or $C$ infection was associated with current alcohol consumption. It seems that only those with ALDH2 1-1 who are smokers consume alcohol. We conclude that smoking and inherited ALDH2 1-1 are the most important determinants of alcohol consumption. In addition to the medical advice of physicians in their yearly health check-ups, worksite health-promotion programs based on both alcohol consumption habits and smoking cessation should be instituted forthwith, particularly for those who demonstrate the potential for developing liver damage. (J Occup Environ Med. 2001;43:701-705)

From the Institute of Health Policy and Management (Ms Lin) and the Institute of Occupational Medicine and Industrial Hygiene (Dr Hsieh, Mr Chen, Dr Cheng), College of Public Health, National Taiwan University; and the Department of Family Medicine, Cathay General Hospital, Taipei (Dr Hsieh).

Address correspondence to: Dr Tsun-Jen Cheng, Institute of Occupational Medicine and Industrial Hygiene, College of Public Health, National Taiwan University, No. 1 Ren-Ai Road, Sec 1, Taipei, Taiwan 10018; e-mail: tcheng@ha.mc.ntu.edu.tw.

Copyright $($ by American College of Occupational and Environmental Medicine olyvinyl chloride production is one of the major industries in Taiwan. ${ }^{1}$ Acknowledging that vinyl chloride monomer exposure has been associated with liver diseases, ${ }^{2,3}$ we have followed a group of polyvinyl chloride workers concerning their liver function since $1992 .^{4,5}$ Previous research has reported that alcohol consumption and hepatitis $B$ and $C$ virus infection may exhibit a synergistic effect on liver damage., 6 Thus, those having experienced hepatitis B and $\mathrm{C}$ infection are advised by occupational physicians of our research group not to drink alcohol, and those demonstrating an abnormal liver function are also advised not to consume alcohol to avoid further liver damage. Studies suggest that those who have or have had advanced liver diseases are more likely to cut down or refrain from alcohol consumption than those who have not, ${ }^{8}$ although it is not clear if asymptomatic subjects will react similarly in situations in which they face risk factors for liver damage or when they experience mildly elevated liver enzyme levels.

Alcohol is oxidized by alcohol dehydrogenase (ADH) into acetaldehyde, which is subsequently oxidized by acetaldehyde dehydrogenase (ALDH) into acetic acid. ${ }^{9}$ Those with alleles $\mathrm{ADH} 2 * 2, \mathrm{ADH} 3 * 1$, and ALDH2*2 have a higher serum acetaldehyde level, resulting from an increased production or decreased elimination of acetaldehyde, which may be associated with discomfort, 
including nausea, headache, and flushing. ${ }^{10}$ Thus, subjects with these susceptible traits are less likely to consume alcohol and become alcoholics. ${ }^{9,10}$ We are not clear, however, as to what extent ALDH2, ADH2, and $\mathrm{ADH} 3$ polymorphisms influence their choice of a low level of alcohol consumption. Allele frequency for ALDH2* 1 is approximately $76 \%$, for $\mathrm{ADH} 2 * 265 \%$, and for $\mathrm{ADH} 3 * 1$ 95\% among Chinese Han. ${ }^{10,11}$ Because the prevalence of $\mathrm{ADH} 3 * 2$ is relatively low for Chinese subjects, only ALDH2 and ADH2 genotypes were included in our study. Smoking is also reported to be strongly associated with alcohol consumption. ${ }^{12}$ To study some of the factors affecting alcohol consumption, we investigated the association of alcohol drinking with smoking, ALDH2 status, previous history of abnormal liver function, and hepatitis $\mathrm{B}$ and $\mathrm{C}$ virus infection among polyvinyl chloride workers.

\section{Methods and Materials}

\section{Subjects and Epidemiology}

A total of 207 male workers from three Taiwanese polyvinyl chloride production plants received interviewer-administered questionnaires to provide information regarding their smoking status, alcohol consumption, and medical and occupational histories. Alcohol drinking was defined as consuming at least one alcoholic beverage each week, with a minimum of $80 \mathrm{~g}$ of alcohol intake each week. Current smoking behavior was defined as an individual having smoked within the preceding 6 months of data collection in 1996. All study subjects had received a medical examination on at least one occasion between 1992 and 1994. Levels of serum aspartate aminotransferase, alanine aminotransferase, and gamma glutamyl transpeptidase, and the immunological status of the hepatitis B virus surface antigen (HBsAg) and anti-hepatitis $\mathrm{C}$ virus antibody (anti-HCV) were obtained from these workers' medical surveillance records logged between 1992 and 1994. Enzymes such as aspartate aminotransferase, alanine aminotransferase, or gamma glutamyl transpeptidase were analyzed with an autoanalyzer (Hitachi 7050, Tokyo, Japan). A history of abnormal liver function was defined as an individual demonstrating serum levels higher than reference values for any of these three liver enzymes on any one occasion. The levels of HB$\mathrm{sAg}$ and anti-HCV were assayed with radioimmunoassay and enzyme-linked immunosorbent assay, respectively. All tests were performed at the National Taiwan University Hospital. Because the number of subjects exhibiting a positive titer for anti-HCV was small, HBsAg and anti-HCV were grouped together as hepatitis virus infection.

\section{Genotypes of ALDH2 and ADH2}

ALDH2-MboII polymorphism. The presence of the ALDH2-MboII polymorphism was determined by a modification of the methods developed in 1993 by Harada and Zhang. ${ }^{13}$ Polymerase chain reaction (PCR) primers were synthesized from the 5' region of exon 12 (5'CAA ATT ACA GGG TCA ACT GCT ATG-3') and the 3' region of exon 12 (3'-CCA CAC TCA CAG TTT TCT CTT-5'). One-half microliter of DNA extracted from peripheral mononucleate cells was added to a PCR buffer containing $200 \mathrm{ng}$ of primers, $1.25 \mathrm{mM}$ magnesium chloride, $0.2 \mathrm{mM}$ of 2'-deoxynucleoside 5'-triphosphates, $50 \mathrm{mM}$ potassium chloride, $10 \mathrm{mM}$ tris(hydroxymethyl)-aminomethane-hydrochloride $(\mathrm{pH}, 8.3)$, and $0.1 \%$ bovine serum albumin in a final volume of $50 \mu \mathrm{L}$. Reaction mixtures were heated for 5 minutes at $95^{\circ} \mathrm{C}$, and $2.5 \mathrm{U}$ of Taq DNA polymerase were then added at $80^{\circ} \mathrm{C}$. Subsequently, 35 cycles of amplification were performed: denaturing at $95^{\circ} \mathrm{C}$ for 1 minute, annealing at $55^{\circ} \mathrm{C}$ for 1 minute, and facilitating extension at $72^{\circ} \mathrm{C}$ for 1 minute. The PCR products were digested with the restriction enzyme
MboII for 8 hours at $37^{\circ} \mathrm{C}$ and were analyzed using $6 \%$ polyacrylamide gel electrophoresis. Homozygous 2-2 individuals displayed a single product fragment of $135 \mathrm{bp}$ following restriction-enzyme digest, whereas homozygous 1-1 individuals expressed 125 and $10 \mathrm{bp}$ fragments, and heterozygous 1-2 individuals revealed the presence of all three fragments.

ADH2-BstU I polymorphism. An $\mathrm{ADH} 2-B s t \mathrm{U}$ I polymorphism was determined by a modification of the methods developed by Chen et al in 1994. ${ }^{11}$ Appropriate primers were synthesized from the 5 region of exon 3 (5'-AATCTTTTCTGAATCTGAACAG-3') and the $3^{\prime}$ region of exon 3 (3'-AGTTGGACCACTGGGGGGAAG-5'). One-half microliter of DNA was added to a PCR buffer containing $200 \mathrm{ng}$ of primers, $1.25 \mathrm{mM}$ magnesium chloride, 0.2 $\mathrm{mM}$ of 2'-deoxynucleoside 5'triphosphates, $50 \mathrm{mM}$ potassium chloride, $10 \mathrm{mM}$ tris(hydroxymethyl)-aminomethane)-hydrochloride $(\mathrm{pH}, 8.3)$, and $0.1 \%$ bovine serum albumin in a final volume of 50 $\mu \mathrm{L}$. Reaction mixtures were heated for 5 minutes at $94^{\circ} \mathrm{C}$, and $2.5 \mathrm{U}$ of Taq DNA polymerase were then added at $80^{\circ} \mathrm{C}$. Subsequently, 35 cycles of amplification were performed: denaturing at $95^{\circ} \mathrm{C}$ for 1 minute, annealing at $55^{\circ} \mathrm{C}$ for 1 minute, and facilitating extension at $72^{\circ} \mathrm{C}$ for 1 minute. The PCR products were digested with the restriction enzyme $B s t \mathrm{U}$ I for 8 hours at $37^{\circ} \mathrm{C}$ and were analyzed with $2 \%$ agarose gel electrophoresis. Homozygous 1-1 individuals revealed a single product fragment of $95 \mathrm{bp}$ following restriction-enzyme digest, whereas homozygous 2-2 individuals expressed 65 and $30 \mathrm{bp}$ fragments, and heterozygous 1-2 individuals displayed all three fragments.

\section{Statistical Analysis}

Data analyses were performed using the Statistical Analysis Systems software package. We used the chisquared and Fisher exact test to com- 


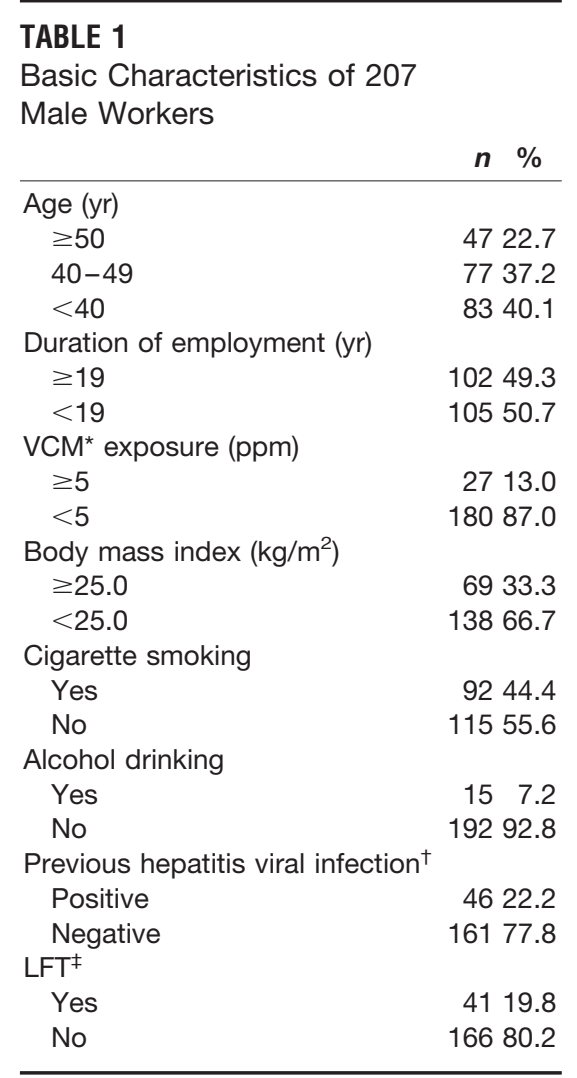

* VCM, vinyl chloride monomer.

+ Hepatitis viral infection, history of positive hepatitis B surface antigen or antihepatitis $C$ virus antibody.

$\ddagger$ LFT, history of abnormal liver function tests, including alanine aminotransferase, aspartate aminotransferase, and $\gamma$-glutamyl transpeptidase.

pare the drinking and non-drinking group data on the basis of age, smoking habits, history of hepatitis virus infection, abnormal liver function status, and genotypes including ALDH2 and ADH2. Subsequently, a logistic regression model was used to express drinking status as a function of a list of potential variables. An odds ratio (OR) for drinking status by ALDH2 and cigarette smoking was also tested using multiple logistic regression.

\section{Results}

The mean age of these 207 male workers was 42.1. Basic characteristics of the study subjects are described in Table 1. Among them, $44.4 \%$ smoked cigarettes, $7.2 \%$ drank more than $80 \mathrm{~g}$ of alcohol each week, $22.2 \%$ revealed a history of previous infection by a hepatitis virus, and $19.8 \%$ revealed a history of abnormal liver function.

The association between drinking status and current smoking status; metabolic genotypes; history of abnormal alanine aminotransferase, aspartate aminotransferase, and gamma glutamyl transpeptidase; and history of HBsAg and anti-HCV is summarized in Table 2. Current smoking was associated with alcohol drinking (OR, 20.5, $P<0.01$ ). Only one ALDH2 1-2 worker consumed alcohol, and none of the ALDH2 2-2 workers consumed alcohol. The ALDH2 1-1 workers demonstrated a higher prevalence of alcohol consumption than those with ALDH2 1-2/2-2 (OR, 10.9, $P<0.01$ ). A similar trend was also found for ADH2 1-1, which was associated with a higher prevalence of alcohol drinking than those with ADH2 1-2/ $2-2$, although the association was not statistically significant. A history of an abnormal liver function test was not associated with alcohol consumption. A positive history of HB$\mathrm{sAg}$ and anti-HCV expression was not associated with alcohol drinking, either. After adjusting for the potential confounders (Table 3), smoking and ALDH2 were statistically significantly associated with alcohol consumption (respectively: OR, 23.3, $P$ $<0.01$ and OR, 14.5, $P<0.05$ ). Further analysis of the OR of drinking status by cigarette smoking and ALDH2 genotypes is referred to in Table 4. Workers with ALDH2 1-2/ 2-2 did not consume alcohol, independently of whether or not they were smokers, apart from the single individual who drank alcohol and was a smoker. Workers demonstrating ALDH2 1-1 status tended to consume alcohol when they were smokers (eg, 13 of 39 individuals), this being far less common for nonsmokers (one of 69 individuals).

\section{Discussion}

ALDH2 deficiency is very common in Orientals, whereas it is rela- tively rare in most other populations. ${ }^{9}$ ALDH2 genotypes affect human drinking behavior and the metabolism of vinyl chloride monomer. In our previous study of polyvinyl chloride manufacturing workers, sister chromatid exchange, a marker of genotoxicity, was positively associated with ALDH2 1-2/ $2-2 .{ }^{14}$ In this study, we focused on the association between ALDH2 and alcohol consumption.

The analysis revealed that ALDH2 1-1 and smoking were significantly associated with alcohol consumption, although neither a history of previous hepatitis virus infection nor a history of previous abnormal liver function seemed to affect alcohol consumption behavior.

In this study, only one worker with an ALDH2 1-2 status and none with ALDH2 2-2 had become regular alcohol users, possibly because of the immediate discomfort associated with drinking alcohol, including nausea and headache. Previous studies have revealed that alcoholism or alcoholic liver disease usually develops for individuals displaying intact ALDH2 enzymes because these subjects lack immediate biological curbs for excessive alcohol consumption. ${ }^{9,10}$ Our study also indicates that even a relatively small amount of alcohol consumption is regulated by the presence of the ALDH2 gene, at least for these Taiwanese workers. A previous report indicates that subjects with ADH2 1-1 are more likely to consume alcohol and become alcoholics ${ }^{10}$; however, workers in our study with ADH2 1-1 were not statistically associated with alcohol consumption. This probably resulted from the small number of ADH2 1-1 subjects in our study.

Alcohol consumption and cigarette smoking are frequently associated with each other, and it is difficult to tell which occurs first. ${ }^{12}$ In our study, the only ALDH2 1-2/2-2 worker who drank alcohol was a smoker, and there was only one nonsmoking ALDH2 1-1 individual who drank alcohol. These findings 


\section{TABLE 2}

Characteristics of Drinking Status of Workers With Potential Confounders*

\begin{tabular}{|c|c|c|c|c|c|}
\hline & \multicolumn{2}{|c|}{$\begin{array}{l}\text { Drinking } \\
(n=15)\end{array}$} & \multicolumn{2}{|c|}{$\begin{array}{l}\text { Non-Drinking } \\
(n=192)\end{array}$} & \multirow[b]{2}{*}{ OR $95 \% \mathrm{Cl}$} \\
\hline & $n$ & $\%$ & $n$ & $\%$ & \\
\hline \multicolumn{6}{|l|}{ Age (yr) } \\
\hline$\geq 50$ & 2 & 13.3 & 45 & 23.4 & $0.40 .1-2.1$ \\
\hline $40-49$ & 5 & 33.3 & 72 & 37.5 & $0.7 \quad 0.2-2.1$ \\
\hline$<40$ & 8 & 53.3 & 75 & 39.1 & Reference \\
\hline \multicolumn{6}{|c|}{ Cigarette smoking } \\
\hline No & 1 & 6.7 & 114 & 59.4 & Reference \\
\hline \multicolumn{6}{|c|}{ Hepatitis viral infection ${ }^{\ddagger}$} \\
\hline Positive & 3 & 20.0 & 43 & 22.4 & $0.90 .2-3.2$ \\
\hline Negative & 12 & 80.0 & 149 & 77.6 & Reference \\
\hline \multicolumn{6}{|l|}{ LFT $^{*}$} \\
\hline Yes & 3 & 20.0 & 38 & 19.8 & $1.0 \quad 0.3-3.8$ \\
\hline $1-1$ & 3 & 20.0 & 17 & 8.8 & $2.60 .7-10.0$ \\
\hline $1-2 / 2-2$ & 12 & 80.0 & 175 & 91.2 & Reference \\
\hline
\end{tabular}

\section{TABLE 3}

Multiple Logistic Regression of

Drinking Status on

Potential Confounders ${ }^{a}$

\begin{tabular}{|c|c|}
\hline & $95 \% \mathrm{Cl}$ \\
\hline \multicolumn{2}{|l|}{ Age (yr) } \\
\hline$<40$ vs $\geq 40$ & $1.60 .5-5.5$ \\
\hline \multicolumn{2}{|l|}{ Cigarette smoking } \\
\hline Yes vs no & $23.32 .9-187.4^{\star \star}$ \\
\hline \multicolumn{2}{|l|}{ Hepatitis viral infection ${ }^{\mathrm{b}}$} \\
\hline $\begin{array}{l}\text { Positive vs negative } \\
\text { LFT }^{\mathrm{c}}\end{array}$ & $0.60 .2-2.7$ \\
\hline $\begin{array}{l}\text { Abnormal vs normal } \\
\text { ALDH2 }\end{array}$ & $1.70 .4-7.7$ \\
\hline $1-1$ vs $1-2 / 2-2$ & $14.51 .8-117.7^{*}$ \\
\hline $\mathrm{ADH} 2$ & \\
\hline $1-1$ vs $1-2 / 2-2$ & $2.40 .5-12.1$ \\
\hline
\end{tabular}

${ }^{\mathrm{a}}$ For definition of abbreviations, see Table 2.

${ }^{\mathrm{b}}$ Hepatitis viral infection, history of positive hepatitis B surface antigen or antihepatitis $C$ virus antibody.

${ }^{c}$ LFT, history of abnormal liver function tests, including alanine aminotransferase, aspartate aminotransferase, and $\gamma$-glutamyl transpeptidase.

${ }^{\star} P<0.05 ;{ }^{\star \star} P<0.01$.

suggest that, apart from genetic determinants discouraging alcohol con- sumption, smoking was the most important factor correlating with Taiwanese workers' drinking status. As in an old Chinese saying, "smoking and drinking are in the same family," the role of cigarette smoking on blue-collar workers' drinking behavior deserves further investigation.

Medical surveillance has been performed periodically on these polyvinyl chloride workers in an occupational safety and health context. Individuals displaying HBsAg or anti-HCV or abnormal liver function have been advised by occupational physicians not to consume any alcohol to prevent potential risk of chronic liver diseases. It was most likely that the lack of immediate discomfort associated with alcohol consumption resulted in the lack of association between alcohol consumption and asymptomatic chronic hepatitis B and C infection. Further, even in the presence of abnormal liver function, those symptomless alcohol-consuming Taiwanese work- ers did not change their drinking behavior. These results indicate that immediate unpleasant biological feedback resulting from the consumption of alcohol is, apparently, more effective than the remote health effect for workers who consume alcohol. ${ }^{15}$ Recent studies have reported that moderate alcohol consumption reduced overall mortality slightly. ${ }^{16,17}$ Such a perception may justify alcohol consumption to certain individuals, even though they may suffer from potential liver damage from long-term alcohol drinking.

We conclude that smoking and inherited ALDH2 1-1 are the most important determinants of alcohol consumption among Taiwanese polyvinyl chloride workers. In addition to medical advice by physicians in these workers' yearly check-ups, worksite health-promotion programs based on both alcohol drinking habits and smoking cessation should be instituted forthwith, particularly for those who 


\section{TABLE 4}

OR of Drinking Status by Cigarette Smoking and ALDH2 Genotype*

Non-Smoking

Smoking ${ }^{\dagger}$

\begin{tabular}{|c|c|c|c|c|c|c|c|c|}
\hline \multirow{2}{*}{\multicolumn{2}{|c|}{ Drinking }} & \multirow{3}{*}{ Non-Drinking } & \multirow[b]{2}{*}{ OR } & \multirow[b]{2}{*}{$95 \% \mathrm{Cl}$} & & & & \\
\hline & & & & & Drinking & Non-Drinking & OR & $95 \% \mathrm{Cl}$ \\
\hline \multicolumn{8}{|c|}{ ALDH2 genotype ${ }^{\ddagger}$} & \\
\hline $1-2 / 2-2$ & $0^{\S}$ & 45 & 0.11 & $0.02-0.53^{\|}$ & 1 & 39 & 0.16 & $0.03-0.77^{\|}$ \\
\hline $1-1$ & 1 & 69 & 0.13 & $0.03-0.66^{\|}$ & 13 & 39 & \multicolumn{2}{|c|}{ Reference } \\
\hline
\end{tabular}

${ }^{*}$ Fisher exact test.

+ Odds ratio (OR) and 95\% confidence interval $(\mathrm{Cl})$ adjusted for age and other potential confounders.

₹ ALDH, aldehyde dehydrogenase.

$\S$ Logistic estimators with a correction of 0.5 .

$\| P<0.01$.

demonstrate the potential for developing liver damage.

\section{Acknowledgments}

We thank Mr Ruey-Hong Wong for his technical assistance and Drs Jung-Der Wang, Ming-Yang Lai, and Keh-Sung Tsai for their clinical assistance. This report was funded in part by Grant NSC 89-2314-B-002-389 from the National Science Council, Taiwan.

\section{References}

1. Department of Economic Affairs. Monthly Report for Production, Shipment and Inventory of Principal Manufacturing Products. Taiwan: Department of Economic Affairs; 1997.

2. World Health Organization. International Program on Chemical Safety. Vinyl Chloride. Environmental Health Criteria 215. Geneva: World Health Organization; 1999

3. Cheng TJ, Huang ML, You NC, Du CL, Chau TT. Abnormal liver function in workers exposed to low levels of ethylene dichloride and vinyl chloride monomer. J Occup Environ Med. 1999;41: $1128-1133$.

4. Huang CY, Huang KL, Cheng TJ, Wang JD, Hsieh LL. The GSTT1 and CYP2E1 genotypes are possible factors causing vinyl chloride-induced abnormal liver function. Arch Toxicol. 1997;71:482-488.

5. Du CL, Kuo ML, Chang HL, Sheu TJ, Wang JD. Changes in lymphocyte single strand breakage and liver function of workers exposed to vinyl chloride monomer. Toxicol Lett. 1995;77:379-385.

6. Villa E, Rubbiani L, Barchi T, et al. Susceptibility of chronic symptomless HBsAg carriers to ethanol-induced hepatic damage. Lancet. 1982;2:1243-1244.

7. Donato F, Tagger A, Chiesa R, et al. Hepatitis B and C virus infection, alcohol drinking, and hepatocellular carcinoma: a case-control study in Italy. Brescia HCC Study. Hepatology. 1997;26:579-584.

8. Zins M, Carle F, Bugel I, Leclerc A, Di Orio F, Goldberg M. Predictors of change in alcohol consumption among Frenchmen of the GAZEL study cohort. Addiction. 1999;94:385-395.

9. Agarwal DP, Goedde HW. The role of alcohol metabolizing enzymes in alcohol sensitivity, alcohol drinking habits, and incidence of alcoholism in Orientals. In: Palmer TN, ed. The Molecular Pathology of Alcoholism. New York: Oxford University Press; 1991:211-237.

10. Chen WJ, Loh EW, Hsu YP, Chen CC, Yu JM, Cheng AT. Alcohol-metabolising genes and alcoholism among Taiwanese Han men: independent effect of $\mathrm{ADH} 2$,
ADH3 and ALDH2. Br J Psychiatry. 1996;168:762-767.

11. Chen SH, Zhang M, Wang NS, Scott CR. Gene frequencies of alcohol dehydrogenase $2(\mathrm{ADH} 2)$ and aldehyde dehydrogenase2 (ALDH2) in five Chinese minorities. Hum Genet. 1994;94:571-572.

12. Shiffman S, Fischer LA, Paty JA, Gnys M, Hickcox M, Kassel JD. Drinking and smoking: a field study of their association. Ann Behav Med. 1994;16:203-209.

13. Harada S, Zhang S. New strategy for detection of ALDH2 mutant. Alcohol Alcoholism. 1993;28(suppl 1A):11-13.

14. Wong RH, Wang JD, Hseih LL, Du CL, Cheng TJ. Effects on sister chromatid exchange frequency of aldehyde dehydrogenase 2 and smoking in vinyl chloride workers. Mutat Res. 1998;420:99107.

15. Potter JD. Hazards and benefits of alcohol. N Engl J Med. 1997;337:17631764.

16. Thun MJ, Peto R, Lopez AD, et al. Alcohol consumption and mortality among middle-aged and elderly US adults. N Engl J Med. 1997;337:17051714.

17. Doll R, Peto R, Hall E, Wheatley K, Gray R. Mortality in relation to consumption of alcohol: 13 years' observation on male British doctors. BMJ. 1994;309:911-918. 